\title{
Respondent-Driven Sampling in Participatory Research Contexts: Participant-Driven Recruitment
}

\author{
Jennifer S. Tiffany
}

\begin{abstract}
This article reports on the use of respondent-driven sampling (RDS) in participatory and community-based research. Participant-driven recruitment (PDR) retains all of the analytic capabilities of $R D S$ while enhancing the role of respondents in framing research questions, instrument development, data interpretation, and other aspects of the research process. Merging the capabilities of RDS with participatory research methods, PDR creates new opportunities for engaging community members in research addressing social issues and in utilizing research findings within community contexts. This article outlines PDR's synthesis of RDS and participatory research approaches, describes how PDR is implemented in community contexts, and provides two examples of the use of PDR, illustrating its process, potentials, and challenges.
\end{abstract}

KEYWORDS Participant-driven recruitment, Respondent-driven sampling, Communitybased participatory research, Participatory research, Action research.

\section{INTRODUCTION}

This article reports on the use of respondent-driven sampling (RDS) in participatory and community-based research. Participant-driven recruitment $(\mathrm{PDR})^{1-3}$ retains the analytic capabilities of RDS (e.g., use of data on personal network sizes and recruiting patterns to control for selection bias and generate population estimates, sampling weights, and standard errors estimates) while enhancing the role of respondents in framing research questions, instrument development, data interpretation, and other aspects of the research process. PDR integrates two distinct research approaches-the practices, analytic methods, and capacity to generate a statistically valid sample associated with RDS and the disciplines and techniques of participatory research including community-based participatory research (CBPR) and participatory action research (PAR).

By merging RDS with participatory research methods, PDR fosters new opportunities for engaging community members in research addressing social issues and in utilizing research findings within community contexts. In particular, it presents opportunities to integrate rigorous participatory methods with rigorous quantitative data analysis.

This article outlines PDR's synthesis of RDS and participatory research approaches, describes how PDR is implemented in community contexts, and provides two examples of the use of PDR illustrating its process, potentials, and

Tiffany is with the HIV/AIDS Education Project, Cornell University College of Human Ecology Family Life Development Center, Ithaca, New York, USA.

Correspondence: Jennifer S. Tiffany, PhD, Director, HIV/AIDS Education Project, Cornell University FLDC, Beebe Hall, Ithaca, NY 14853, USA. (E-mail: jst5@cornell.edu) 
associated challenges. The emphasis of the article is on field methodology, rather than on RDS data analysis.

\section{FOUNDATIONS OF PDR}

PDR developed through the integration of RDS with participatory research techniques. Key elements of RDS that distinguish it from other forms of chainreferral sampling include direct contact between recruiter and recruit (in contrast to referrals mediated through the researcher), presence of a pre-existing reciprocal relationship between the recruiter and recruit, documentation of recruitment patterns, regulation of the number of recruits per recruiter, and collection of data regarding participants' personal network sizes. ${ }^{4}$ Early in the development of RDS, as a way to engage injection drug users and other hidden populations in HIV prevention studies, researchers noted that peer-to-peer recruiting often led to informal peer education, resulting in a mild intervention effect. ${ }^{5}$ This paved the way for the development of a number of peer-driven interventions ${ }^{6}$ and suggested that RDS held potential as a sampling method in participatory research on social issues.

Participatory research projects have investigated international development issues, ${ }^{7}$ organizational change, ${ }^{8,9}$ community development and advocacy needs, ${ }^{10}$ health care and community health promotion, 5,11,12 environmental health and urban design, and social issues affecting adolescent health and development. ${ }^{13-17}$

Participatory research approaches developed, in part, as a response to conditions of exclusion, oppression, and marginalization ${ }^{18}$ and, in part, as a strategy for addressing and compensating for some limitations of traditional research methods, enhancing the validity and utilization of research findings. Participatory approaches such as action research and empowerment evaluation are now practiced and discussed theoretically across a wide range of disciplines, including public health. ${ }^{11,12,19}$ Participatory research often engages those who are the focus of policies and programs to study the issues and conditions that affect their lives. Participatory methods also are used to research conditions within organizations, identifying issues and facilitating the development of strategies for resolving them. ${ }^{8}$ These approaches seek to elicit diverse perspectives, often using multiple research methodologies, including methods that promote discussion, deliberation, the development of critical thinking, and the exploration of social circumstances related to research questions. Participatory research seeks to generate knowledge that can be used to prompt collective action and change; its premise is that research should be useful to communities, organizations, programs and participants at the same time as contributing to the academic and disciplinary literatures. ${ }^{9}$

Often, participatory research approaches seek to involve marginalized people in determining research questions and methods and in interpreting and utilizing research findings. Participatory research draws on local knowledge and emphasizes the involvement of non-academics. In particular, it seeks to mobilize and build upon the expertise of those whose lives are directly affected by the research issue. ${ }^{10}$ Ideally, stakeholders in participatory research stand positioned to act upon the new knowledge they have collectively generated. Action may occur at individual, interpersonal, organizational, and policy levels. ${ }^{13}$ If participants and communities involved in the research have access to data and findings, this may enable more nuanced data interpretation as well as higher commitment to utilizing results and to exploring emergent research questions. Research efforts that are viewed as sensitive 
to community concerns, locally engaged and sustained rather than extractive, may be better received by community members and potential respondents. ${ }^{11,20}$ Participatory research efforts often unfold over a relatively long period, and community-based participatory researchers have articulated crucial elements and stages that characterize effective collaborations. ${ }^{11}$

Participatory research faces a number of specific challenges: Careful negotiation of power dynamics between academic researchers and community members, as well as among community stakeholders, is crucial. Communication among partners is key and can be problematic (e.g., academic researchers may be ill-equipped to readily understand community concerns and priorities; community members may not readily endorse academic concerns about statistically valid samples). The creation of a "common language" and common standards of practice, including standards for sampling and data integrity, by the research team is a long, iterative, demanding process.

The synthesis of RDS with participatory research approaches contributes to resolving some of these challenges, in particular by providing a rigorous sampling technique that can present participatory researchers with a means to develop statistically credible samples without diminishing the quality of community engagement. RDS produces more reliable data than convenience or snowball samples through the use of data on personal network sizes and recruiting patterns to control for bias. In some cases, it generates more comprehensive data than either venue or institutional samples. ${ }^{21}$ Because RDS utilizes social networks and gives participants a central role in recruiting, it is more consistent with the values of participatory research than random sampling. Further, the involvement of participants in the sampling process opens up opportunities for dialogue and education regarding issues like data integrity, informed consent, and the overall aims of the research.

At first conceived as a sampling methodology, RDS worked to engage disenfranchised and stigmatized people in HIV prevention studies, giving them a central role in recruiting and building upon their capabilities and strengths. ${ }^{6}$ Nonetheless, the initial studies using RDS were not explicitly framed as participatory research efforts. We propose PDR as a careful synthesis of the two approaches. PDR provides a context for RDS that is specifically adapted to the framework and demands of participatory research, while at the same time maintaining the core elements of RDS.

\section{DESCRIPTION OF PDR}

As in other participatory research approaches, studies using PDR may be initiated by either researchers or community stakeholders or may develop out of an on-going collaboration. In any of these cases, PDR involves a number of stages, shown in Figure 1, that situate the peer recruiting effort within a participatory research process that seeks to ensure both the relevance of the research aims to community stakeholders and the utilization of research findings.

\section{Community Engagement, Referral of "Seeds" and Pilot Activities}

In most participatory research projects, researchers collaborate with informal and formal stakeholder organizations to set and refine the research questions and aims. In PDR, these organizations also identify a limited number of potential study 


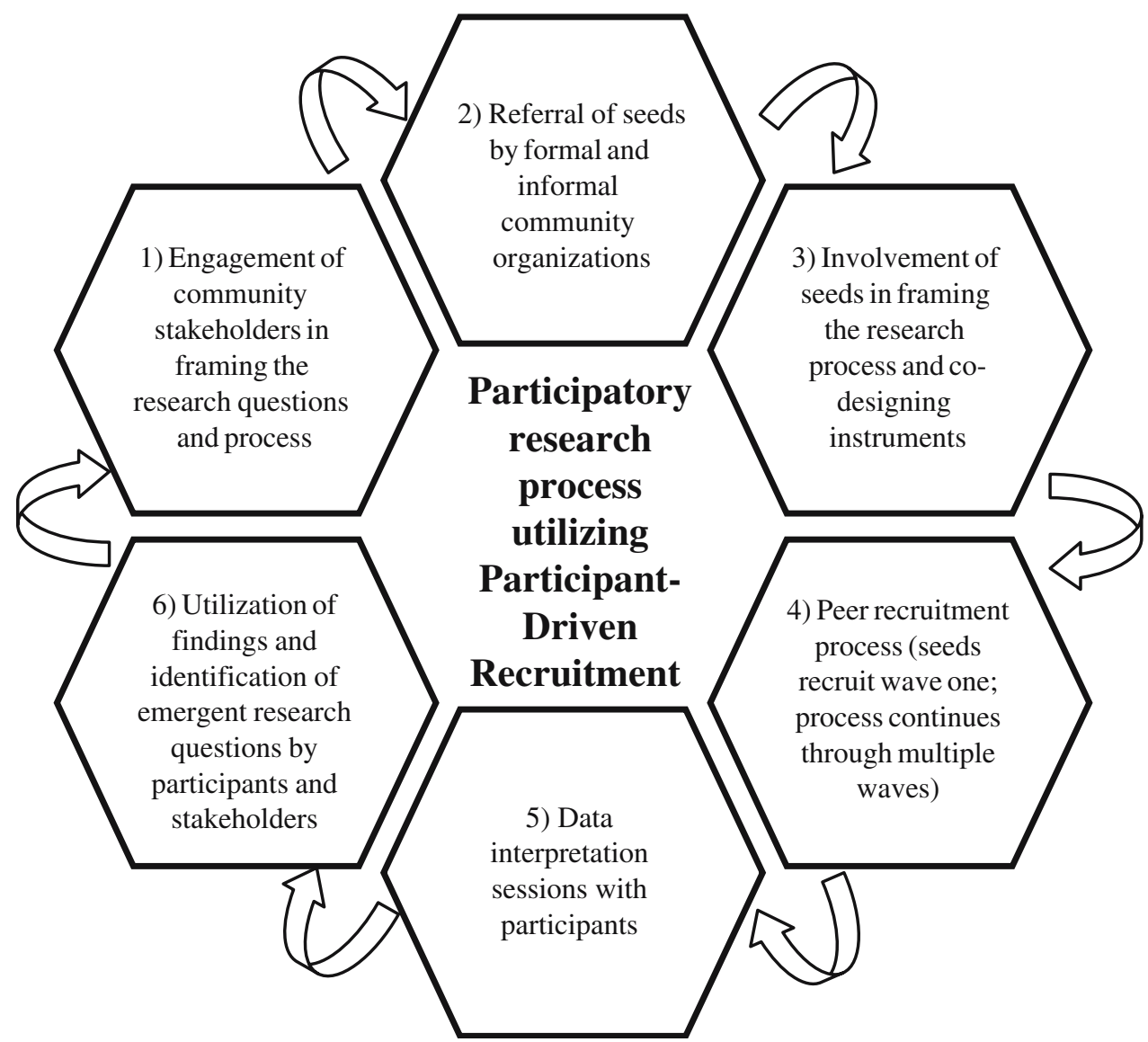

FIGURE 1. Stages of a participatory research process utilizing PDR.

participants with diverse perspectives ${ }^{21}$ to pilot, review, and assist in the revision and adaptation of research materials and questionnaires and to serve as "seeds" (the foundation of the peer recruitment process). The seeds in PDR have a pivotal role in the research process, involving several responsibilities and opportunities for engagement in addition to their roles as respondents and peer recruiters in RDS. Seeds take part in pilot groups to discuss the aims of the study and to assess and fine-tune research instruments, in some cases substantially co-designing the instruments in close collaboration with academic researchers.

The involvement of community members in the design and development of research projects has multiple benefits and challenges that have been well articulated in the community-based participatory research literature. ${ }^{20}$ Engaging seeds in discussions regarding the design and implementation of the study enhances their familiarity with the research process and contributes to the incremental development of a "common language" by diverse members of the research team. Increasing the commitment of seeds to the overall research project assists in addressing challenges regarding recruiting rates and productivity of seeds encountered in some RDS studies: ${ }^{22}$ The engagement and sense of ownership of the research by the seeds appears to lead to higher commitment to and capacity for peer recruitment and aids in developing recruiting momentum. It also helps to address 
challenges faced by participatory researchers: Peer recruitment enhances the level of engagement of participants in the overall research process by creating new opportunities for formal and informal dialogue about the research issues.

\section{Peer Recruitment}

After the pilot process has been completed, seeds recruit the first wave of participants, and peer recruitment continues through at least the number of waves required to obtain equilibrium. ${ }^{23}$ The recruiting process is generally similar to that in most studies using RDS, with the following differences: In most RDS studies, peer recruiters receive coupons with serial numbers and contact information for the research project, which they distribute to their recruits. In PDR, peer recruiters also receive written explanations of the research project, informed consent materials, and, in some cases, survey instruments and self-addressed stamped envelopes to convey to their recruits. In PDR studies that include group discussion or educational sessions, participants may have opportunities to discuss and/or roleplay recruiting techniques.

\section{Incentives}

Participants receive small incentives for taking part in the study (e.g., \$15 for survey completion) and for recruiting their peers (e.g., $\$ 10$ for successfully recruiting an eligible participant). In addition to these extrinsic incentives, engagement with the overall development of the research project and the interpretation and utilization of findings may serve as an additional incentive, fostering intrinsic interest and motivation among participants. Evaluations of PDR indicate that, while the availability of extrinsic incentives initially attracted participants, they stayed engaged based on intrinsic motivation, the quality of participation, opportunities to discuss important issues with peers, or interest in the questions addressed by the research. In the words of one adolescent participant:

At the beginning, I wanted the money, but now it's turned into something totally different.... It surprises me-so much has changed. I've been able to meet people that I know I wouldn't have met [otherwise]. I've been able to expand and learn, you know, get more involved in things that I like to do and hope to do in the future. $^{2}$

\section{Location}

Most RDS studies have a research office or storefront location where recruits meet individually with research staff to assess their eligibility, complete informed consent documents, be interviewed, and, in some cases, receive an educational session. In PDR, self-administered surveys and educational or discussion sessions may take place in a wide range of community settings identified as accessible during the pilot process. While this may reduce costs associated with space rental and help to reduce the "geographic filtering" 24 of RDS samples, it demands extra care in terms of participant confidentiality and data integrity (see below).

\section{Data Interpretation and Utilization}

PDR participants are invited to attend periodic updates on the research and data interpretation meetings. As preliminary findings are developed, community stakeholders as well as participants take part in further data interpretation meetings, 
discussion regarding the study's results, and activities leading to the dissemination and utilization of findings.

\section{Confidentiality and Management of Data Regarding Recruiting Patterns}

Because PDR research is relatively decentralized, special care is taken to explain informed consent, confidentiality, and other human subjects considerations to participants and to recruiters; participants and other community members who are highly engaged in the research complete the same human subjects tutorial required of academic researchers. Participant referrals provide a tangible link between participants and their recruiters; participants describe their relationship with the person who recruited them in order to ensure that it is reciprocal. ${ }^{21}$ Contact forms facilitate follow-up and payment of incentives. Personally identifying information is kept separately from research data sets, which include unique identifiers for recruiters and recruits; all data is stored in secure locations at the university.

\section{EXAMPLES}

Two studies conducted by research teams including the author illustrate the process and challenges of implementing PDR. The first involved dislocated workers in a study of social protections and employment trajectories; the second involved adolescents in community-based HIV prevention research. Instruments and procedures for both studies were approved by the Cornell University Committee on Human Subjects. Findings from both studies have been reported elsewhere ${ }^{2,3,25-30}$; the emphasis here is on the field methodology. The aims of the studies and the rationale for utilizing PDR in each of them are briefly summarized below. A chart comparing the use of PDR in the two studies is presented in Table 1.

\section{Dislocated Workers}

PDR was developed in response to challenges encountered during a plant closure study conducted during 2000-2001. A non-unionized manufacturing plant employing nearly 500 people was shut down in early 1998 as a consequence of corporate restructuring. The plant had been the beneficiary of a variety of local economic development assistance packages in a community that had experienced the closure and downsizing of many other manufacturing firms. The study aimed to engage approximately 50 former workers in an extensive survey about their post-closure employment trajectories in order to inform ongoing social protection, planning and economic development efforts and to serve as a corrective to studies of the local impacts of the plant closure that neglected to gather data regarding dislocated workers. $^{31}$ The former employees were in effect a hidden population; no comprehensive list could be obtained to serve as a sampling frame although human resource records provided precise aggregate demographic information on the displaced workers. Further, a proportion of the workers had moved out of state after the closure, either relocating to other plants owned by the original firm or traveling in search of employment opportunities. Peer recruitment exceeded the original participation objective, engaging 72 dislocated workers in the study. PDR had the capacity to build upon the social connections among former workers to locate study respondents while simultaneously providing a context for the participants to explore, reflect upon, and deliberate about economic development strategies, employment trajectories, and measures of job quality. RDS analysis of 
the data aided in estimating post-closure out-migration rates. By combining RDS and participatory research methods, the study enabled an economically vulnerable population to contribute to the development of recommendations regarding community social protection and economic development programs.

\section{Rural Adolescents}

The second illustration of PDR is drawn from an HIV prevention study of rural adolescents. Peer recruitment slightly exceeded the original sampling objective (128 youth participated; the study enrollment goal was 125). Although many approaches may be taken to sampling adolescents, peer recruiting produces empirical data about social networks that cannot be gathered in institutional or venue samples ${ }^{21}$; our study engaged homeless and out-of-school youth as well as youth enrolled in all local schools. RDS enables study of adolescents' social networks-in particular, the relationship of risk and protective characteristics and behaviors to social networks. With empirical evidence of recruiting patterns, both demographic and nondemographic characteristics can be mapped in relation to recruiting networks. This enabled us to explore the roles that risk and protective characteristics play in the social network structures of adolescents. ${ }^{32,33}$ Further, RDS analysis contributes to identifying sub-groupings of adolescents, work that is crucial to the development of effective tailored interventions. ${ }^{34}$ PDR enabled not only the gathering of data on recruiting patterns needed for RDS analysis but also engaged youth in a participatory learning process that was particularly appropriate to their developmental needs. ${ }^{2,30,33}$

\section{CHALLENGES AND LESSONS LEARNED}

There are a number of challenges involved in implementing PDR, these include fully utilizing RDS analysis during data interpretation sessions, addressing location sensitivity so that sampling is not distorted by lack of access to study sites, and preventing the emergence of "super recruiters" without dampening participants' engagement in the overall study.

\section{RDS Analysis}

Both of the examples reported drew on early versions of RDS analysis software. This aided in identifying and addressing specific issues (e.g., the relative disengagement of contingent workers from permanent employees' social networks, the strong tendency of rural youth to recruit other rural youth). RDS analysis requires significant data set preparation before data can be imported and used with the current specialized software package (Respondent Driven Sampling Analysis Tool (RDSAT) can be downloaded at no cost from http://www.respondentdrivensampling.org). In the two studies cited, detailed RDS analyses were completed after recruitment ended and after most community-based discussions of the research had taken place. Deliberate procedures for incorporating RDS analyses into early data interpretation efforts are needed in order for community-based partnerships to benefit fully from the use of this sampling method. ${ }^{35}$

\section{Location Sensitivity}

The participatory processes that are well integrated into PDR may assist in addressing the location sensitivity and "geographic filtering" 24 of RDS-based samples. Useful practices include soliciting guidance from study participants on accessible times, 
TABLE 1. Comparison of the use of PDR in two studies

\begin{tabular}{|c|c|c|}
\hline & Plant closure study & $\begin{array}{l}\text { Rural adolescent HIV } \\
\text { prevention study }\end{array}$ \\
\hline \multicolumn{3}{|l|}{ Engagement } \\
\hline $\begin{array}{l}\text { Community organizations } \\
\text { involved in framing } \\
\text { research and in } \\
\text { recruiting seeds }\end{array}$ & $\begin{array}{l}\text { Workforce Improvement Board, } \\
\text { Workers Rights Council, } \\
\text { YWCA }\end{array}$ & $\begin{array}{l}\text { Youth Bureau, } \\
\text { Catholic Charities, } \\
\text { Aid to Victims of } \\
\text { Violence, Jacobus } \\
\text { Center } \\
\text { (reproductive } \\
\text { health clinic), YWCA }\end{array}$ \\
\hline $\begin{array}{l}\text { Number of seeds involved } \\
\text { in pilot process }\end{array}$ & 7 & 9 \\
\hline \multicolumn{3}{|l|}{ Peer recruitment } \\
\hline Duration & Summer 2000-spring 2001 & Winter 2001-spring 2002 \\
\hline Projected sample size & 50 & 125 \\
\hline Actual sample size & 72 & 128 \\
\hline Number of waves & 5 & 7 \\
\hline $\begin{array}{l}\text { Distributed informed } \\
\text { consent materials }\end{array}$ & Yes (informed consent only) & $\begin{array}{l}\text { Yes (parental consent } \\
\text { as well as informed } \\
\text { consent/assent) }\end{array}$ \\
\hline \multicolumn{3}{|l|}{ Incentives } \\
\hline For completing survey & $\$ 15$ & $\$ 15$ \\
\hline $\begin{array}{l}\text { For recruiting new } \\
\text { participant }\end{array}$ & $\$ 10$ & $\$ 10$ \\
\hline Steering incentives & $\begin{array}{l}\$ 20 \text { (for recruiting dislocated } \\
\text { workers who had held } \\
\text { part-time or contingent positions; } \\
\text { for recruiting dislocated workers } \\
\text { who had moved out } \\
\text { of state to seek jobs) }\end{array}$ & None \\
\hline Locations & $\begin{array}{l}\text { Workforce Improvement Board, } \\
\text { Workers Rights Council, } \\
\text { restaurants, private residences; } \\
\text { data interpretation } \\
\text { sessions held in meeting rooms } \\
\text { at Fire Hall and YWCA }\end{array}$ & $\begin{array}{l}\text { Youth Bureau, YWCA, } \\
\text { Rural Services meeting } \\
\text { room, classrooms } \\
\text { in rural school }\end{array}$ \\
\hline Location sensitivity & $\begin{array}{l}\text { None (surveys could be } \\
\text { self-administered and mailed in; } \\
11 \% \text { of participants were living } \\
\text { out-of-state at the time of } \\
\text { the survey) }\end{array}$ & $\begin{array}{l}\text { Significant (in rural areas } \\
\text { close to survey sites, } \\
\text { participant pool was } \\
\text { saturated, while rural } \\
\text { areas distant from } \\
\text { survey sites were } \\
\text { under-represented) }\end{array}$ \\
\hline \multicolumn{3}{|l|}{ Data interpretation } \\
\hline $\begin{array}{l}\text { Formal meetings with } \\
\text { participants to review } \\
\text { preliminary data }\end{array}$ & Yes & Yes \\
\hline $\begin{array}{l}\text { Formal meetings with } \\
\text { stakeholder organizations } \\
\text { to review findings }\end{array}$ & $\begin{array}{l}\text { Yes (separate meetings } \\
\text { with each agency) }\end{array}$ & $\begin{array}{l}\text { Yes (group presentation } \\
\text { and meetings on-site } \\
\text { with some agencies) }\end{array}$ \\
\hline
\end{tabular}


TABLE 1. Continued

Plant closure study

Rural adolescent HIV prevention study

\begin{tabular}{lcc}
$\begin{array}{c}\text { Written report } \\
\text { to participants } \\
\text { Local media coverage }\end{array}$ & Yes & No \\
$\begin{array}{c}\text { Yes (researcher, agencies } \\
\text { and participants) } \\
\begin{array}{c}\text { Presentations and } \\
\text { publications outside } \\
\text { the local community }\end{array}\end{array}$ & $\begin{array}{c}\text { Nos (co-authored with } \\
\text { participants) }\end{array}$ \\
$\begin{array}{l}\text { Individual or organizational } \\
\text { actions taken by } \\
\text { participants attributed } \\
\text { to involvement in research }\end{array}$ & Yes & Yes \\
\hline
\end{tabular}

locations, and methods of survey administration. For example, surveys can be administered in community locations recommended by participants as accessible sites rather than at a centrally located research office or storefront. Pilot studies may suggest a protocol in which respondents are provided with self-administered questionnaires and informed consent materials to give or mail to other potential participants, facilitating engagement of participants who might otherwise be missed by the study (e.g., dislocated workers who moved out of state after a plant closure).

\section{"Super Recruiters"}

Regulating the number of participants that can be recruited by any one peer is a core element of RDS, generally accomplished by setting recruiting quotas and limiting the amount of recruiting materials (e.g., coupons) offered to each participant. In many studies, highly committed participants emerge who are eager to promote the study and to recruit more new participants than their quota allows. In PDR, potential "super recruiters" can be engaged in elements of the participatory study other than recruiting, such as organizing data interpretation sessions or disseminating research findings within the community.

\section{CONCLUSIONS}

PDR relies on the careful implementation of the core elements of RDS. Additional defining elements of PDR include recruitment of diverse seeds through formal or informal stakeholder organizations, involvement of seeds in piloting and co-designing study instruments and procedures, human subjects education for community research partners, involvement of participants and stakeholders in data interpretation sessions, and dissemination of findings to inform local actions. Some of these elements are specific to PDR; some are more general attributes of participatory or empowerment approaches. ${ }^{36}$

PDR seeks to enable eligible participants to make informed judgments about their own level of engagement in the study of potentially sensitive social issues. PDR creates formal and informal contexts for civic discussion that are accessible to research participants who might not attend community meetings or utilize other traditional means of voicing their experiences and views. It creates a socially embedded research process in which discussion of the research questions may take 
place when peers meet informally (e.g., while shopping) as well as during formal data interpretation sessions. Being recruited by peers to take part in a research project serves for some as a bridge to civic engagement and fosters intrinsic interest in the questions and issues explored by the study. Thus, this approach to recruiting members of hidden, vulnerable, and marginalized populations to participate in research projects can contribute to more inclusive community dialogue about social issues and strengthen community participation in research efforts.

\section{ACKNOWLEDGEMENTS}

I am grateful to many people for conversations about the issues, ideas, and methods discussed in this article, particularly: Lourdes Beneria, Cynthia Coleman, Bev Brown, Doug Heckathorn, Deladem Kusi-Appouh, Josephine Allen, Eunice Rodriguez, Jane Powers, Hélène Grégoire, Keiko Goto, Patricia Enekwe, Amy Bianchi, and Alexanderia Stebbins. The study involving rural youth was funded by the Cooperative State Research, Education and Extension Service, USDA (Agricultural Experiment Station Project \#NYC-324410). Any findings, conclusions or recommendations expressed in this publication are those of the author and do not necessarily reflect the view of the USDA. This article is dedicated to the memory of Beverly A. Brown.

\section{REFERENCES}

1. Heckathorn DD, Rosenstein JE. Group solidarity as the product of collective action: creation of solidarity in a population of injection drug users. In: Thye SR, Lawler EJ, eds. Advances in Group Processes. Group Cohesion, Trust and Solidarity. Greenwich, Connecticut: JAI; 2002;19:37-66.

2. Bianchi A, Bishara D, Enekwe P, et al. Friends inviting friends: participant-driven recruitment in an HIV prevention research project. CYD J. 2003;4(1):26-31.

3. Tiffany J, Allen J, Bianchi A, Block J, et al. Using participant-driven recruitment to involve rural adolescents in HIV prevention research. Paper presented at American Public Health Association annual meeting, November 2006, Philadelphia, Pennsylvania.

4. Magnani R, Sabin K, Saidel T, Heckathorn DD. Review of sampling hard-to-reach and hidden populations for HIV surveillance. AIDS. 2005;19(Supplement 2):S67-S72.

5. Semaan S, Lauby J, Liebman J. Street and network sampling in evaluation studies of HIV risk reduction interventions. AIDS Rev. 2002;4:213-223.

6. Heckathorn DD, Broadhead RS, Anthony DL, Weakliem DL. AIDS and social networks: prevention through network mobilization. Sociol Focus. 1999;32:159-179.

7. Chambers R. Whose Reality Counts? Putting the First Last. London: Intermediate Technology; 1997.

8. Greenwood D. Industrial Democracy as Process: Participatory Action Research in the Fagor Cooperative Group of Mondragón. Stockholm, Sweden: Swedish Center for Working Life; 1991.

9. Greenwood D, Levin M. Introduction to Action Research: Social Research for Social Change. Thousand Oaks, California: Sage; 1998.

10. Cornwall A, Gaventa J. From Users and Choosers to Makers and Shapers: Repositioning Participation in Social Policy. Brighton, England: Institute of Development Studies; 2001.

11. Israel BA, Schulz AJ, Parker EA, Becker AB. Review of community-based participatory research: Assessing partnership approaches to improve public health. Annu Rev Public Health. 1998;19:173-202.

12. McKoy CB, Achi R, Wolfe HP, Crandall LA. The CDRC principles of international health research. J Urban Health. 2005;82:iv5-iv8. 
13. Goto K. The application of a participatory approach in health and nutrition programs: A case study of an HIVIAIDS prevention initiative among youth [Dissertation]. Ithaca, New York: Cornell University; 2004.

14. Campbell C, MacPhail C. Peer education, gender and the development of critical consciousness: participatory HIV prevention by South African youth. Soc Sci Med. 2002;55:331-345.

15. Maglajlic RA, Tiffany JS. Participatory action research with youth in Bosnia and Herzegovina-"everyone who is here talks openly and without fear, hoping that we will help other adolescents through our work." J Community Pract. 2006;14(1-2):161-180.

16. Sy-ar M. An evaluation of a participatory action research approach to involving youth in HIVIAIDS awareness campaigns in Haiti [Thesis]. Ithaca, New York: Cornell University M.P.S.; 2004.

17. Sabo K. Youth participatory evaluation: a field in the making. New Dir Eval. 2003;98:1-10.

18. Freire, P. Pedagogy of the Oppressed. New York, New York: Herder \& Herder; 1970.

19. Kidd SA, Kral MJ. Practicing participatory action research. J Couns Psychol. 2005; 52:187-195.

20. Minkler M. Ethical challenges for the "outside" researcher in community based participatory research. Health Educ Behav. 2004;31:684-697.

21. Ramirez-Valles J, Heckathorn DD, Vasquez R, Diaz RM, Cambell RT. From networks to populations: the development and application of respondent-driven sampling among IDUs and Latino gay men. AIDS Behav. 2005;9(4):387-402.

22. Wang J, Carlson RG, Falck RS, Siegal HA, Rahman A, Li L. Respondent-driven sampling to recruit MDMA users: a methodological assessment. Drug Alcohol Depend. 2005;78 (2):147-157.

23. Ramirez-Valles J, Heckathorn DD, Vasquez R, Diaz RM, Cambell RT. The fit between theory and data in respondent-driven sampling: response to Heimer. AIDS Behav. 2005;9(4):409-414.

24. Heckathorn DD, Semaan S, Broadhead RS, Hughes JJ. Extensions of respondent-driven sampling: a new approach to the study of injection drug users aged 18-25. AIDS Behav. 2002;6(1):55-67.

25. Tiffany JS. Insights from a plant closing: dislocated workers and economic development planning. Planners Network. 2001;148.

26. Beneria L, Santiago LE. The impact of industrial relocation on displaced workers: a case study in Cortland, New York. Econ Dev Q. 2001;15:78-89.

27. Beneria L. Gender, Development, and Globalization: Economics as if all People Mattered. New York, New York: Routledge; 2003.

28. Tiffany JS. Lives, livelihoods, and economic development planning: The impact of the Rubbermaid plant closing on dislocated workers in Cortland, NY [Dissertation]. Ithaca, New York: Cornell University; 2004.

29. Allen J, Rodriguez E, Tiffany JS. Lessons from HIV prevention efforts: Using a participant-driven recruitment strategy in rural upstate New York. Paper presented at National HIV Prevention Conference, Atlanta, Georgia; 2005.

30. Powers J, Tiffany JS. Engaging youth in participatory research and evaluation. J Public Health Manag Pract. In press.

31. Saratoga Associates. Cortland county special economic development and adjustment assistance program. Report submitted to Cortland County Industrial Development Agency, Cortland, New York; 2000.

32. Kirke DM. Chain reactions in adolescents' cigarette, alcohol and drug use: similarity through peer influence or patterning of ties in peer networks? Soc Netw. 2004;26:3-38.

33. Kusi-Appouh D. Contextual factors influencing sexual activity within adolescent social networks in a micropolitan/rural area [Masters Thesis]. Ithaca, New York: Cornell University; 2006.

34. Pantin H, Prado G, Schwartz SJ, Sullivan S. Methodological challenges in designing efficacious drug abuse and HIV prevention interventions for Hispanic adolescent subgroups. J Urban Health. 2005;82:iii92-iii102. 
35. Salagnik MJ, Heckathorn DD. Sampling and estimation in hidden populations using respondent-driven sampling. Sociol Method. 2004;34(1):193-240.

36. Wallerstein $\mathrm{N}$. What is the evidence on effectiveness of empowerment to improve health? Copenhagen, WHO Regional Office for Europe, 2006 (Health Evidence Network Report, http://www.euro.who.int/Document/E88086.pdf, accessed February 1, 2006). 